\title{
Ein Bein zu viel
}

\section{Erhard Taverna}

Dr. med., Mitglied der Redaktion

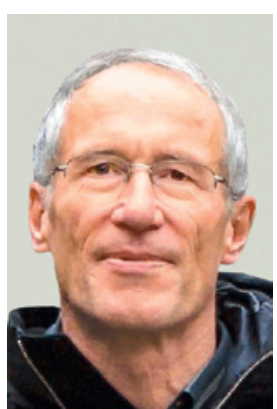

Er nannte sich John. Ein kräftiger Mann, der beim Betreten der Praxis stets lässig mit zwei Fingern an seinen Stetson tippte. Ein Diabetiker mit einem tadellos gepflegten Beinstumpf, den er im Sprechzimmer fast liebevoll auspackte. Ein tragischer Autounfall auf den Philippinen hatte zur Amputation über dem linken Kniegelenk geführt. Das war die offizielle Version des gefragten Ingenieurs und Vielfliegers. Er kam damit erstaunlich gut zurecht und schien zufrieden mit sich und der Welt. Wenn ihm die Fragerei zu lästig wurde pflegte er Matthäus zu zitieren: «So aber deine Hand oder dein Fuss dich ärgert, so haue ihn ab und wirf ihn von dir.» Was als zynischer Scherz aufgefasst wurde kam der Wahrheit sehr nahe. John hatte sich absichtsvoll und für teures Geld sein gesundes Bein amputieren lassen.

Mit sichtbaren Zwangssituationen haben wir keine Mühe, doch die inneren Notlagen, die zu verstümmelnden Handlungen führen, strapazieren unser Verständnis. Zum Beispiel Menschen mit einem BIID-Syndrom, was für Body Integrity Identity Disorder steht. Wo noch vieles nicht klar ist, beruhigt zumindest ein medizinischer Fachausdruck. Es sind vorwiegend gut ausgebildete Männer, die in den Fernen Osten reisen, um sich ein gesundes Bein, überwiegend das linke, amputieren zu lassen. Gemäss Selbsthilfeforen im Internet ist der Wunsch nach einer Amputation, einer Blendung oder gar einer Querschnittslähmung gar nicht so selten. Die Fachsprache hat dafür den Begriff «Xenomalie», Fremdgliedrigkeit, geprägt. Es handelt sich dabei um psychiatrisch unauffällige Menschen, die schon vor der Pubertät über eine quälende Körperwahrnehmung klagen. Für weitere Syndrome einer gestörten Integrität zwischen Körper und Selbst gibt es zahlreiche Begriffe. Am verbreitetsten ist die fehlende Geschlechtsidentität, bekannt als Gender Identification Disorder GDI, bei der eine operative und hormonelle Geschlechtsumwandlung legal ist und von den Krankenkassen, zumindest teilweise, bezahlt wird. Davon unterschieden werden die Apotemnophilie, die sexuelle Erregung durch eine imaginierte oder reale Amputation, die Misoplegie, der Hass auf einen eigenen Körperteil, bis hin zur Extremform des Cotard-Syndroms, wo Menschen sich für tot halten. Cotard, ein französischer Neurologe, hat 1880 erstmals dieses Krankheits- bild beschrieben, das bei schwer Depressiven, Schizophrenen oder durch Schlaganfälle, Epilepsie oder Hirntumoren Geschädigten vorkommen kann. Was diese Patienten mit dem Xenomalie-Syndrom gemeinsam haben, sind mit PET oder mit einem Magnetenzephalogramm MEG nachweisbare Veränderungen der Gehirnaktivität in Bereichen des Stirn- und Scheitellappens und des prämotorischen Cortex. Da diese Netzwerke meist in der rechten Hirnhemisphäre lateralisiert sind, korrelieren Amputationswünsche mit linksseitigen Körperteilen. Die anatomischen Auffälligkeiten, die zusammen mit genetischen und sozialen Faktoren komplexe Ursachen vermuten lassen, erlauben bis heute keine kausale Behandlung, es sei denn als Letztes die Amputation. Die Erfolge sprechen für sich. Gemäss einer Befragung von 21 Betroffenen zwischen 23 und 73 Jahren, nach erfolgter Operation im Ausland, waren alle zufriedener als zuvor. Sie hatten zum Teil Schwierigkeiten, sich im neuen Alltag zurecht zu finden, doch keiner bereute seine Entscheidung. Dürfen Ärzte gesunde Körperteile entfernen, wenn der Leidensdruck Betroffener nach erfolgter Amputation deutlich und möglicherweise lebenslänglich nachlässt? Psychotherapie oder Medikamente sind meistens erfolglos. Wer sein Bein loswerden will, greift auch einmal zur Kettensäge, schädigt sich mit Trockeneis oder bindet seine Gliedmassen ab. Während Transsexualität mit oder ohne medizinische Betreuung weitgehend akzeptiert ist, bleibt die Entfernung «überflüssiger» Körperteile aus einem fehlerhaften Körperschema umstritten. Ein Verein zur Förderung von Studien über Körperidentitätsstörungen möchte das ändern, Internetforen bringen Menschen mit BIID und deren Angehörige zusammen. Auch wenn die Schätzungen über die Häufigkeit dieser Störungen weit auseinandergehen, die Debatte über das Recht auf Selbstverstümmelung ist längstens auch in der Schweiz angekommen.

\section{Literatur}

- The desire for healthy limb amputation - structural brain correlates and clinical features of xenomelia, Brain 2012, 3. Oktober, Prof. Brugger, USZ.

- www.forum.biid.ch www.vfsk.eu 